\title{
Hormone therapy after endometrial cancer
}

\author{
A O Mueck and H Seeger
}

Section of Endocrinology and Menopause, Women's University Hospital, Tuebingen, Germany

(Requests for offprints should be addressed to A O Mueck, Department of Endocrinology and Menopause, Women's University Hospital, Tuebingen, Calwer Strasse 7, 72076 Tuebingen, Germany; Email: endo.meno@med.uni-tuebingen.de)

\begin{abstract}
Endometrial carcinoma is listed under the absolute contraindications to hormone therapy (HT). According to current opinion, HT after stage I or II is still considered an option, and continuous combined oestrogen/progestogen replacement therapy (CCEPT) would be recommended. However, up to now, only observational studies have been put forward. Although none of these studies have established an increased rate of recurrence or mortality, alternatives such as phytopreparations and tibolone, or particular psychotherapeutic drugs, such as venlafaxine, should be considered for the relief of climacteric complaints. Progestogen-only therapy (PT) particularly has been considered. However, the currently discussed possible progestogen effects regarding an increased risk of breast cancer have to be taken into account. Indeed, the wider discussion about the gestagen effects regarding the risk of breast cancer is to be considered. Generally, after hysterectomy, at least for patients with cardiovascular risk factors, the preference today is to use low-dose oestrogen therapy (patches or gels) instead of CCEPT, and this is also now recommended for patients after endometrial cancer. This is to be noted because of the risk factors for endometrial carcinoma, such as hypertension, obesity, polycystic ovary syndrome (PCO) and diabetes mellitus. However, each form of HT should be only exceptionally recommended, and the patients must be informed about the risks that exist and the use of alternatives.
\end{abstract}

Endocrine-Related Cancer (2004) 11 305-314

\section{Introduction}

The most common age for diagnosis of endometrial cancer (ECa) is 62-70 years of age (mean 67 years); however, 20$25 \%$ of these neoplasias appear pre-menopausally (Arbeitsgemeinschaft Krebsregister 2002). This early appearance of the disorder means obligatory operative therapy, with hysterectomy and bilateral salpingo-oophorectomy resulting in an iatrogenic, surgically induced menopause. The abrupt loss of oestrogen gives rise to corresponding deficiency symptoms, especially hot flushes, sleep disorders and depressive mood, greatly reducing quality of life. Consequently, the possibility of oestrogen replacement therapy after ECa must be considered. However, in addition to this, older women may also suffer from the consequences of oestrogen deficiency, with urogenital complaints and osteoporosis, so the question of oestrogen replacement also applies to them.

\section{Present strategies - to be changed?}

Hormone therapy (HT) can be administered by oestrogen-only therapy (ET) or oestrogen progestogen therapy
(EPT) - the latter in the form of combined sequential EPT (CSEPT) or combined continuous EPT (CCEPT) (terminology according to Sturdee 2003). In the data sheets (summary of product characteristics) for such HT preparations, ECa is listed as a contraindication to therapy for ET alone, as well as for EPT, and also when the diagnosis was made many years before and the treatment therapy was obviously successful. Nevertheless, for 25 years, more patients are being treated with HT (preferably CCEPT) after therapy for ECa, mostly limited to FIGO stage 1 , also more rarely to stage 2 . Since up to $80 \%$ of all ECa are found to be stage 1 at the time of diagnosis (Arbeitsgemeinschaft Krebsregister 2002), many women may have the option of HT.

In the following discussion, it shall be pointed out how far HT (ET or EPT) after ECa has been investigated in studies and how the risks of HT are currently estimated, that is, after premature stopping of the Women's Health Initiative study (evidence level I). In our opinion, new findings clearly show that the current recommendations of using HT after ECa preferably as EPT regimens should be thought about respectively and differentiated. Since the 1980s, ECa has not been listed under absolute 
Figure 1 Description of the levels of evidence*

\begin{tabular}{ll}
\hline Level I & properly randomised controlled trials \\
Level II-1 & well-designed controlled trials without randomisation \\
Level II-2 & $\begin{array}{l}\text { well-designed cohort or case-control analytic study } \\
\text { multiple time series with or without intervention (e.g. cross-sectional and uncontrolled investigational studies) }\end{array}$ \\
Level II-3 & $\begin{array}{l}\text { uncontrolled experiments with dramatic results } \\
\text { opinions of respected authorities that are based on clinical experience, descriptive studies and case reports; } \\
\text { reports from expert committees }\end{array}$
\end{tabular}

*According to the definition of the Preventive Services Task Force 1996, used in official statements of the North American Menopause Society (NAMS 2003).

contraindications in the relevant consensus statements (German Society of Endocrinology 1988, 1996, American College of Obstetricians and Gynecologists 1993, 2001, Birkhäuser et al. 2003), although it is clearly stated that in the absence of prospective, randomised studies the effect of HT on the recurrence of ECa remains unknown. This assessment has obviously not been altered up to now (Creasman 1999), in contrast to new recommendations about HT after breast cancer (e.g. Chlebowski \& McTiernan 1999, Natrajan et al. 1999, Emons 2002, Marsden 2002, Pritchard et al. 2002, Mueck \& Wallwiener 2003).

Yet, for example, the negative gestagen effects, possibly on the breast, proved to deteriorate metabolism and the vessels, are to be taken into great consideration. This can bring into question the usual preference for combined hormone treatment (EPT instead of ET) after ECa. Possible alternatives, such as particular psychotherapeutic drugs or phytotherapy, tibolone and raloxifene, must also be discussed in this context, with assessment of use and risks, certainly always under the aspect that the most efficacious and sole causal treatment of menopausal complaints is represented by oestrogen.

\section{Oestrogen dependency-ECa type I}

In the developed world, ECa is the most frequent cancer of the female genital tract. In the USA, it was projected that 39300 new cases would occur in 2002 and about 6600 women would die from the disease (American Cancer Society 2002). In Germany, the incidence per year is estimated to be about 10000 cases, and ECa is the fourth most frequent malignancy in women after breast, colon, and rectal carcinoma (Arbeitsgemeinschaft Krebsregister 2002). Regarding oestrogen dependency, the ECa type I can be distinguished; it is associated with hyperoestrogenicity or oestrogen dominance (the risk factors are adipositas, anovulation, early menarche and late menopause) and is often preceded by hyperplastic endometrial changes. At the molecular level, mutation of the ras oncogene, depletion of the expression of tumour suppres- sor genes and disturbances in the function of DNA repair genes play a central role (Emons \& Schulz 1998, Oehler et al. 2003). In contrast, ECa type II is not associated with hyperoestrogenicity and typically develops from the atrophic endometrium of post-menopausal women. Here mutation of the p53 gene seems to be important. Presumably, sex steroids are not crucial for the genesis of type II.

Recently, endometrial low-grade stromal sarcomas were found to be sensitive to oestrogens. Notably, over $50 \%$ were observed to be pre-menopausal, and the relapse rate, after bilateral ovariectomy and subsequent high-dose gestagen therapy, was greatly reduced. Accordingly, based on these studies (evidence level II-3), tumours of this primary type are considered a contraindication to HT (Römer \& Mueck 2002).

Oestrogens work as typical tumour promoters in the formation of type 1 carcinoma. Through mitogenic activity, they increase the probability of endometrial hyperplasia, with possible progressive transformation to (mostly well-differentiated) carcinoma. Further mutations (in the p53-gene, loss of the expression of oestrogen and progesterone receptors, among other things) favour the transformation to more aggressive malignant, undifferentiated carcinoma with correspondingly worse prognosis (Oehler et al. 2003). It has recently been recognised that particular oestrogen metabolites are significant in the genesis of hormone-dependent tumours (Liehr 2000, Emons et al. 2003). In this context, we could demonstrate (studies of evidence levels I and II-1) that the kind and quantity of the metabolites can differ depending on the administered HT, and that they can also be strongly influenced by exogenous factors, such as smoking (Mueck et al. 2002, Mueck \& Seeger 2003).

\section{ECa during $\mathrm{HT}$ - primary risk}

It is well recognised that the primary risk of ECa can be reduced through a combination of oestrogen therapy (ET) with gestagen every cycle for a minimum of 10 , or even better, 12-14 days (evidence level II-1-3) (Grady et al. 
Table 1 Risk of endometrial cancer despite combination with progestogen? Relative risk (95\% confidence interval) in the studies

\begin{tabular}{llll}
\hline First author & ET & SCEPT & CCEPT \\
\hline Grady 1995 & $2.3(2.1-2.5)$ & Cohort studies & -1 \\
$\quad$ Meta-analysis & $9.5>10$ years & RR 0.2-0.9 & \\
30 trials $>$ Case control studies & \\
Pike 1997 & & RR 0.9-2.0 & $1.1(0.8-1.4)$ \\
Weiderpass 1999 & $2.2(1.9-2.5)$ & $1.9(1.3-2.7)$ & $0.2(0.1-0.8)$ \\
Persson 1999 & $6.2(3.1-12.6)$ & $2.9(1.8-4.6)$ & - \\
Beresford 1997 & $4.2(2.5-8.4)$ & $1.4(0.6-3.3)$ & $1.3(0.8-2.2)^{2}$ \\
$>5$ years & $4.0(3.1-5.1)$ & $1.4(1.0-1.9)$ & $2.5(1.1-2.2)$ \\
Hill 2000 & - & $3.7(1.7-8.2)$ & $0.6(0.3-1.3)$ \\
\hline
\end{tabular}

EPT: oestrogen progestogen therapy; CEE:-conjugated equine oestrogens; SCEPT: sequential combined EPT with $\geq 10$ days of progestrogen addition (mostly CEE $0.625-1.25 \mathrm{mg}$ combined with MPA $5 \mathrm{mg}$ ); CCEPT: continuous combined EPT (mostly CEE $0.625 \mathrm{mg} / \mathrm{MPA} 2.5 \mathrm{mg}$ ).

${ }^{1}$ Persistent risk 5 years after withdrawal of HT. Missing mean values for combination with progestogens; no data with CCEPT.

2 Progestogen addition during 10-21 days per month.

1995) (Table 1). With long-cycle (spacing out) therapy, an increased risk cannot be excluded (Bjarnason et al. 1999), although we and others did not observe this (Rabe et al. 1997, Erkkola et al. 2002) (evidence level II-1). However, increased risk has also been demonstrated with addition of monthly sequential progestogen (SCEPT), in contrast to CCEPT (Weiderpass et al. 1999, Hill et al. 2000) (evidence level II-2). For instance, in a study by Sturdee et al. (2000), 1312 women were treated with sequential HT with at least 10 days of progestogen (evidence level II-2); there was a $6 \%$ prevalence of complex or even atypical hyperplasia. In contrast, there was no case of hyperplasia among 1196 biopsies in women treated for 9 months with CCEPT (Kliogest), and complex hyperplasia arising during previous sequential HT was converted to normal endometrium by CCEPT.

Indeed, the question of whether the risk with CCEPT is lower than with no treatment is to be investigated in further clinical trials, because, in the present studies, only a relatively small number of patients are represented. It is certain that with oestrogen monotherapy, after metaanalysis of over 30 studies (Grady et al. 1995) (evidence level II-1-3) a two- to fourfold risk, with long-term therapy (10 years) a 10 -fold relative risk is calculated, also with lower doses $(0.3 \mathrm{mg}$ equine oestrogen has a five- to eightfold risk!). The elevated risk also remains for at least 5 years after stopping oestrogen therapy (Grady et al. 1995).

Oestriol can also increase the risk, presumably only with oral administration; however, this is relevant to those with repeated rather than once-daily dosing (Bertone \& Weiderpass 2000) (evidence level II-2). In contrast to this, the risk is negligible with vaginal (topical) dosing of oestriol, but only in compliance with the respective specified dosages. Therefore, the usual commercial products can be used for local treatment of high-risk patients after ECa with appropriate explanation; in doing so, the use of oestriol can be recommended.

\section{HT after ECa - clinical trials}

According to the latest official statements of the North American Menopause Society (2003), the treatment of moderate to severe menopause symptoms (vasomotor symptoms and sleep disruption from vasomotor symptoms) remains the primary indication for systemic ET and EPT. In women who have been treated previously for endometrial cancer, these benefits must be weighed against the risk of stimulating tumour growth and recurrence. There is no available evidence based on randomised clinical trial for an estimation. The situation is comparable to the question of applying HT after breast cancer; here too results of well-designed studies are lacking (Pritchard et al. 2002). For a definite conclusion that HT after ECa is not deleterious, a large randomised trial of 1000-2000 patients per arm would be necessary to rule out an increase of cancer recurrence of $10 \%$ or greater for HT (Chlebowski \& McTiernan 1999). According to the latest 'ACOG committee opinion' (ACOG 2001), in the absence of HT a well-differentiated neoplasm of endometrioid cell type with superficial invasion would entail an approximate 5\% risk of recurrent disease, and a moderately differentiated neoplasm with up to one-half myometrial invasion a $10-15 \%$ risk.

Indeed, so far, only five controlled studies exist to our knowledge. The essential outcomes are listed in Tables 2 and 3. All studies are retrospective, non-randomised case/ control studies (evidence level II-2). These studies produced no data showing that a higher risk exists with HT after treated ECa. On the contrary, in these studies, a 
Table 2 Hormone therapy after endometrial cancer FIGO stage I or II - case control studies

\begin{tabular}{|c|c|c|c|c|}
\hline First author & $n /$ controls & $\begin{array}{l}\text { ET/EPT } \\
\text { (cases/controls) }\end{array}$ & $\begin{array}{l}\text { Duration HT } \\
\text { (mean) }\end{array}$ & $\begin{array}{l}\text { Recurrences } \\
\text { n/controls }\end{array}$ \\
\hline Creasman 1986 & $47 / 174$ & ET:CEE & $\begin{array}{l}26 \text { Months } \\
\text { (3-84 months) }\end{array}$ & $2 \% / 15 \%{ }^{1}$ \\
\hline Lee 1990 & $44 / 99$ & $\begin{array}{l}\text { EPT/CEE } \\
15 / 29\end{array}$ & $\begin{array}{l}64 \text { Months } \\
\text { (2 months-11 years) }\end{array}$ & $0 \% / 8 \%{ }^{2}$ \\
\hline Chapman 1996 & $62 / 61$ & $\begin{array}{l}\text { CCEPT/CEE } \\
33 / 29\end{array}$ & $\begin{array}{l}\text { 39.5 Months } \\
\text { (3-107 months) }\end{array}$ & $3 \% / 10 \%{ }^{3}$ \\
\hline Suriano 2001 & $75 / 75$ & $\begin{array}{l}\text { CCEPT/CEE } \\
37 / 38\end{array}$ & $\begin{array}{l}83 / 63 \text { Months } \\
\text { (mean) }\end{array}$ & $1 \% / 15 \%{ }^{4}$ \\
\hline
\end{tabular}

HT: hormone therapy=ET or EPT; ET: oestrogen-only therapy; EPT: oestrogen/progestogen therapy; SCEPT: sequential combined EPT; CCEPT: continuous combined EPT; CEE: conjugated equine oestrogen.

${ }^{1}$ ET: CEE $0.625-1.25 \mathrm{mg} /$ day vaginal (72\%); CEE $0.625-1.25 \mathrm{mg} /$ day oral, cyclically (15\%), orally (cyclically), vaginal (topical) applications (13\%).

2 No details regarding progestogen.

${ }^{3}$ One patient with estradiol patch, one patient with vaginal CEE, 60 patients with CEE orally $0.625 \mathrm{mg} /$ day; in 33 patients, combination with MPA $2.5 \mathrm{mg} / \mathrm{day}$.

${ }^{4} 15 \%$ of cases and controls FIGO stage IIA, IIIA or IIIB. Progestrogen addition in $49 \%$ of the patients ( $80 \%$ MPA $\left.2.5 \mathrm{mg} / \mathrm{day}\right)$

tendency towards a decrease or a significant decrease in the frequency of relapses was seen, as well as longer disease-free intervals and to some extent also longer survival times.

The first study by Creasman et al. (1986) is most frequently cited. However, it is often not mentioned that $72 \%$ of 47 women with ET (conjugated equine oestrogens (CEE) $0.626-1.25 \mathrm{mg}$ ) were treated vaginally. Only 13 patients were treated with oral CEE, obviously without the addition of progestogens. On average, cyclical ET lasted 26 months (3-84 months), starting after surgical therapy with a mean of 15 months (0-81 months). The risk factors for ET and the control group (174 patients) were distributed equally, especially regarding prognostic factors such as tumour grade, nodal status and receptor status. The ER positive were (ET/control) $85 / 73 \%$ and the PR positive $78 / 63 \%$ (n.s.). The main results of this study were a significantly lower recurrence and mortality rate $(2 \%$ vs $15 \%)$ with a longer disease-free interval $(P<0.05)$ during ET.

In the study by Lee et al. (1990), 44 women with ECa stage I were treated exclusively with oral CEE (0.625$1.25 \mathrm{mg} /$ day; cyclically) (ET), and $35 \%$ of them received sequential progestin addition (SCEPT; no details). Twothirds of the women started HT (ET, SCEPT) in the first year, and the others later than 2 years after surgical therapy. HT lasted, on average, 64 months (2 months-11 years). During HT, no relapses or deaths were observed. In contrast, the recurrence and mortality rate was $8 \%$ in the control group of 99 patients.

In the study by Chapman et al. (1996), patients with stage II ECa were also included for the first time, showing

Table 3 Hormone therapy before and after endometrial cancer - retrospective study of C. Lauritzen, Ulm (Germany)

\begin{tabular}{|c|c|c|c|c|}
\hline SCEPT & $n$ & $\begin{array}{l}10 \text { years survival } \\
(\%)\end{array}$ & Years of survival & Years until recurrence \\
\hline Controls & 83 & 83 & 6.3 & 3.4 \\
\hline \multirow[t]{2}{*}{ SCEPT after surgery } & 37 & 88 & 7.8 & 3.8 \\
\hline & & 95 & 9,7 & 4.1 \\
\hline SCEPT before and after surgery & 41 & $P=0.5^{+}$ & $P=0.04^{+}$ & $P=0.08^{+}$ \\
\hline \multicolumn{5}{|l|}{ Stage II (age 50-66 years) } \\
\hline SCEPT & $n$ & $\begin{array}{l}10 \text { years survival } \\
(\%)\end{array}$ & Years of survival & Years until recurrence \\
\hline Controls & 71 & 70 & 6.4 & 2.4 \\
\hline \multirow[t]{2}{*}{ SCEPT after surgery } & 42 & 76 & 7.6 & 3.9 \\
\hline & & 81 & 8.8 & 4.8 \\
\hline SCEPT before and after surgery & 27 & $P=0.04^{+}$ & $P=0.07^{+}$ & $P=0.05^{+}$ \\
\hline
\end{tabular}

${ }^{+}$Significant vs controls.

SCEPT: Sequential combined oestrogen progestogen therapy. 
a significantly better prognosis in the HT group in terms of staging and invasiveness of the tumours. Details on the receptor status are lacking; otherwise, the risks were distributed equally. On average, oral CEE $(0.625 \mathrm{mg} /$ day $)$ was started within 8 months (0-108 months); after 5 months' treatment, 33 of the 62 patients of the HT group $(53 \%)$ received a progestin (CCEPT), 80\% MPA $2.5 \mathrm{mg} /$ day. The duration of HT was 39.5 months (3-107 months). There were two recurrences (3\%). In the control group of 61 patients, six recurrences were observed (10\%), one and four patients respectively died (two patients from ECa). These differences were not significant. Accordingly, the difference in disease-free survival failed to reach significance $(P=0.07)$, probably due to the low patient number.

In a recent study by Suriano et al. (2001), 75 out of 249 women with ECa after surgery were treated with HT and carefully matched with 75 control patients; there were no differences in age, parity, tumour stage and grading, histology, lymph node stage, surgical therapy and radiation. The ECa-risk groups were also comparable in hypertension, diabetes and obesity; data on receptor status, however, are lacking. The majority of the women had FIGO stage IB, and $15 \%$ of each group had the advanced stages IIA, IIIA or IIIB. The exclusion criteria were stage IV and ECa while receiving tamoxifen.

Within 12 months, $73 \%$ of all patients started with ET (the rest within 5 years), 'mostly' CEE $0.625 \mathrm{mg} /$ day (no details), $49 \%$ continuously combined with MPA $2.5 \mathrm{mg} /$ day (CCEPT?). The mean observational time was 83 months, and 63 months for the control. During HT (ET and EPT), two recurrences (1\%) were observed, restricted to the pelvic area, in contrast to eight local recurrences and three cases of distant metastasis in the control group $(15 \%)$. The disease-free interval was significantly protracted in the HT group. Regarding a possible protective progestogen effect, no definite conclusion could be drawn due to the low recurrence frequency in the HT group; the same holds true for the mortality.

In addition to the four studies listed in Table 2, there is one retrospective, non-randomised case/control study (evidence level II-2) by Lauritzen (1993). In total, 147 women were treated with EPT (no details) and followed up for 10 years after ECa (Table 3). Prognosis was comparable in the groups, but data on receptor status are missing. For cancer stage I, with EPT after ECa the mean survival was 7.8 years; with EPT before and after surgery, the mean survival was 9.7 years, significantly longer than for controls (6.3 years). Similar results were observed in patients with stage II.

Finally, two observational studies without control groups (evidence level II-3) have been conducted with 31 and 20 patients respectively, which did not indicate any enhanced risk during HT (Baker 1990, Bryant 1990). Thus, according to our knowledge, we have summarised all published studies with definite examination of HT after ECa. So far, the only prospective, randomised study has been under way in the USA since 1998, as introduced in 1997 during the Annual Meeting of the American College of Obstetrics and Gynecology. In a double-blind design, CEE $0.625 \mathrm{mg} /$ day (oral) is being compared with placebo. Each study arm will comprise 1000 women after ECa stages I or II and will last 3 years - in the year 2002 so far only 400 patients were recruited in each arm (AR Genazzani, personal communication). Interestingly, this important study is being conducted with ET, in contrast to all recommendations up to now and to clinical experience from the last 25 years preferring (continuous combined) EPT.

In the literature we could find only one case report published about exacerbation of ECa in patients treated with HT (evidence level II-3). During treatment with $0.625 \mathrm{mg}$ equine oestrogen (without progestogen), within 1 year after surgery, abdominal metastasis developed of ER-positive, well-differentiated ECa (stage I) (Carr et al. 1996). Overall, hardly any data support the argument against administration of HT after ECa. According to the evidence of these studies (evidence level II-2, II-3), it seems likely that HT is not contraindicated in ECa stage I or II. However, selection bias may play an important role in all non-randomised studies, since the physician will prefer to offer HT to patients with better prognosis. There is a strong need for further assessment of the safety of HT after ECa by prospective, randomised trials.

\section{PT — an alternative strategy?}

For all forms of endometrial hyperplasia, including atypical hyperplasic adenomatosis, a therapy trial with gestagens (PT) is justified. According to observational studies (evidence level II-1-3), even higher stages of ECa can be treated with moderate to high doses of gestagen, in which case, non-aromatised gestagens, such as MPA (100-500 mg) or megestrol acetate (40-120 mg), should be used. Thus, menopausal complaints can also be alleviated or abolished.

However, gestagens in the lowest doses (5-10 mg MPA; 20-40 mg megestrol acetate) may also be considered. There is experience of their efficacy, especially with hot flushes, in patients treated for breast cancer. Thus, every PT is surely inferior to oestrogen replacement (ET or EPT), and clinical experience shows that relatively frequent treatment failures are seen. In controlled studies, however, strikingly frequent significant improvements were demonstrated with PT (Table 4), with a 60-90\% reduction in hot flushes, though also with high placebo 
Table 4 Treatment of hot flushes with progestogeon-only therapy - prospective, randomised placebo-controlled trials

\begin{tabular}{lrlll}
\hline & $n$ & Progestogen & \multicolumn{2}{l}{ Reduction of the frequency of hot flushes (\%) } \\
\cline { 4 - 5 } First author & & Progestogen & Placebo \\
\hline Bullock 1975 & 57 & MPA & 90 & 25 \\
Morrison 1980 & 34 & MPA & 68 & 20 \\
Albrecht 1981 & 6 & MPA & 87 & 25 \\
Schiff 1980 & 32 & MPA & 74 & 26 \\
Loprinzi 1994 & 80 & MA & 85 & - \\
Quella 1998 & 58 & MA & 89 & 26 \\
\hline
\end{tabular}

MPA: medroxyprogesterone acetate; MA: megestrol acetate.

effects (Bullock et al. 1975, Morrison et al. 1980, Schiff et al. 1980, Albrecht et al. 1981, Loprinzi et al. 1994, Quella et al. 1998, Farish et al. 2000). Based on these studies, representing results on evidence level I, corresponding trials with PT to treat climacteric symptoms are therefore also justified.

Experiences with low-dose gestagen therapy (PT) to treat hot flushes after ECa are scarce; up to now, CCEPT has been recommended and considered relatively free of risk. In our opinion, however, this must be questioned on various grounds, for certain patient groups at least.

Thus, the new discussion of gestagens in connection with the risk of breast cancer is also significant for the choice of therapy after ECa. So far, we have proceeded on the assumption that all oestrogen preparations entail an increased risk of breast cancer. In the case of a decision to treat menopausal symptoms with HT, a gestagen would mostly be combined (CCEPT), or alternatively a PT, such as megestrol acetate, would be implemented (Chlebowski \& McTiernan 1999, Natrajan et al. 1999, Marsden 2002, Pritchard et al. 2002, Mueck \& Wallwiener 2003). However, regarding the assessment of the risk of recurrent cancer, the current data on PT compared with EPT are so limited (evidence level II-2-3) that, recently, in Germany, according to a consensus statement of the German Society of Senology, the two regimens were rated equal in entailing relapse risk after the treatment of breast cancer (Emons 2002, Mueck \& Wallwiener 2003). Nevertheless, EPT is naturally much more effective than PT for the treatment of hot flushes (studies according evidence level I).

These critical judgements of gestagens are supported by the fact that in the current part of the Women's Health Initiative study carried out only with ET (without gestagen), in women who have had a hysterectomy, no increased breast cancer risk was seen after 5 years (evidence level I). Furthermore, a series of new studies has recently been published that estimate an increased risk of breast cancer, specifically through the gestagen component of EPT, particularly with use of CCEPT (evidence level II-1-2). Altogether, the current data are certainly still very controversial; in our opinion, the gestagen effect in relation to the breast cancer risk cannot be finally commented on yet (Kenemans 2000, Marsden 2002, Seeger et al. 2003). Nevertheless, a potentially raised risk of breast cancer through the gestagen component must be included in the individual use/risk-analysis in the future. Should it be confirmed in further studies that gestagens increase the risk of breast cancer, we should not favour EPT in the future after ECa, but rather ET.

According to current studies, there are patients for whom we prefer to recommend ET without combination with gestagen, independently of the breast cancer issue: hysterectomised patients with a high cardiovascular risk should not receive a gestagen, and here a series of (above all, vascular) negative effects can be clinically very relevant. Thus, in the 'Heart and Oestrogen/Progestin Replacement Study (HERS)' (evidence level I), those receiving $\mathrm{HT}$, in comparison to placebo, had a higher rate of reinfarction, which is associated with gestagen effects such as vasoconstriction or mobilisation of arteriosclerotic plaques. In our opinion, this is also valid for the Women's Health Initiative (evidence level I) - here, likewise, a group with higher cardiovascular risks was treated that certainly for the most part had arteriosclerotic vessel changes (age over 60 years, 66\%; smokers, 50\%; hypertension, $36 \%$; $\mathrm{BMI}>30 \mathrm{~kg} / \mathrm{m}, 34 \%$ ).

It is well known from epidemiological studies, just as from experimental studies (evidence level I), that, in contrast to women with preexisting atherosclerosis, for cardiovascular healthy women no gestagen-dependent risk has to be considered (Mikkola \& Clarkson 2002). For example, in double-blind, placebo-controlled trials, we could prove that the vessels in healthy women react immediately and adequately to a vasoconstrictive stimulus through reactive dilatation, while in women after infarction, the endothelial reserve is drastically reduced (Mueck et al. 1999). For this reason, our current recommendation of ET, instead of EPT, to treat menopausal symptoms after ECa applies primarily to women with cardiovascular 
disease. This is, however, of great practical relevance, counting hypertension, diabetes mellitus, metabolic syndrome, polycystic ovary syndome and obesity as the most important risk factors for ECa that simultaneously produce an increased cardiovascular risk! Thus, the options for PT as an alternative to HT will be considerably reduced.

\section{Raloxifene or tibolone - after ECa?}

The treatment of ECa usually includes ovariectomy, which increases the risk of coronary heart disease (CAD) and osteoporosis. For prevention and therapy of CAD, statins are the first choice (Hillard 2000); for osteoporosis, bisphosphonates, as well as raloxifene, can be considered (evidence level I). So far, no data are known to us that could prohibit the use of raloxifene after ECa. In contrast to tamoxifen, raloxifene does not have a proliferative effect on endometrium (Hillard 2000) (evidence level I), and, as far as we know, there are no reports of increased risk of ECa under raloxifene treatment. Nevertheless, ECa is listed in the data sheet for raloxifene as an absolute contraindication to treatment, 'as safety in this patient group has not been adequately studied'. This may be based on the fact that, up to now, only small numbers of cases are available from studies with endometrial biopsies before and after therapy.

Likewise tibolone, according to the existing studies (evidence level I, II-1), has no proliferative effect on the endometrium (Kloosterboer \& Sands 2000). However, like breast cancer, ECa is listed as a contraindication in the data sheet for tibolone. In comparison to raloxifene, tibolone offers the advantage of effectively treating both menopausal and urogenital oestrogen deficiency complaints. With the use of tibolone after ECa, however, the same legal, realisable patient information as with HT must be given i.e. informed consent regarding "off label" use after ECa, especially because, in comparison to HT, hardly any clinical data on these risks exist for tibolone. However, because the experimental studies are promising, it is justifiable to consider tibolone as an alternative.

\section{Management of hot flushes - nonhormonal alternatives}

From a legal point of view, it appears wise to consider alternatives which do not have hormone-dependent neoplasias listed as contraindications. The German Society of Senology recently recommended treatment with selective serotonin-reuptake inhibitors (SSRIs), such as venlafaxine or fluoxetine, after breast cancer (Emons 2002, Mueck \& Wallwiener 2003). In fact, it has been proved through randomised, placebo-controlled trials that there is a positive efficacy against hot flushes (evidence level I). The tricyclic antidepressant opipramol is also effective; it has been used in Germany for years to treat menopausal complaints, and is particularly well tolerated (Mueck \& Stoll 2001). The antiepileptic gabapentin has also been shown to reduce hot flushes; this was only recently demonstrated in the first double-blind, placebo-controlled trial (Guttuso et al. 2003).

Other non-hormonal alternatives are methyldopa, clonidine, veralipride (an antidopaminergic), lipophilic beta-blockers such as propranolol, tranquilisers or related substances (such as belladonna and ginseng), and vitamin E (Albertazzi 2002). Only a few studies on these substances (evidence levels I and II-1-3) have shown an efficacy strikingly better than in clinical practice. Therefore, we do not recommend these substances as alternatives to HT.

Currently, the most effective alternatives seem to be the SSRIs. They can, however, have side effects such as nausea, constipation, dry mouth, central nervous system effects, and - as recently reported - gastrointestinal bleeding. Besides this, there have been reports of an increased risk of suicide, because the elimination rate can be too fast in some patients, leading to acute withdrawal symptoms. After breast cancer, SSRIs may be prescribed instead of HT, but this is based on another risk/benefit situation (Chlebowski \& McTiernan 1999, Pritchard et al. 2002, Mueck \& Wallwiener 2003). However, at present, for use after ECa, we would favour SSRIs over HT only when the patient refuses HT after informed consent, because its safety profile is, in our opinion, not as favourable.

Certainly, the use of various herbal compounds, such as phytoestrogens and dietary supplements, is of growing significance, although the risk of endometrial hyperplasia or ECa cannot be excluded (Johnson et al. 2001) (evidence level II-3). Therefore, hormone-dependent neoplasias are listed as contraindications for many of these products. The compositions of the phytopreparations, such as those from soya, isoflavonoids, red clover, Cimifuga extract, agnus castus and St John's wort, are indeed complex, variable and only partly known. The actions of the active ingredient have also been little investigated; for example, the recent verification of the first clinically very relevant interactions with St John's wort. Generally, the actions, such as side effects, are hard to determine. Accordingly, the study outcomes are also controversial; therefore, a variety of studies (evidence level I) have been published.

In analyses and relevant consensus statements on the basis of over 1000 publications (evidence levels I and II), the possibility of replacing HT with phytopreparations is assessed in a more reserved manner (North American Menopause Society 2000, Glazier \& Bowman 2001). A 
treatment trial - before use of HT - is nevertheless worthwhile. Phytopreparations are socially well accepted, and, with longer treatment, satisfactory effects can be attained in some women, because of the high compliance of women in therapy with plant-based preparations ('natural products')

\section{Conclusion and practical recommendations}

HT can be given after treatment of ECa stage I or II - this is undoubtedly the most effective and the only causal treatment of menopausal estrogen deficiency symptoms. However, there is a strong need to determine the safety of HT after ECa in prospective, randomised trials, which have yet to be done. Up to now, only non-randomised case/ control studies and uncontrolled investigational studies have been available; that is, the recommendations are based on studies with evidence levels II-2, II-3 and III. Therefore, it is appropriate that ECa is listed as a contraindication in all data sheets, and patients must be informed of this. This also applies to tibolone and raloxifene and a large number of the phytopreparations. Gestagens have been proposed for high-dose treatment of disseminated ECa and also in lower doses for the management of hot flushes. Furthermore, relatively efficacious alternatives are particular psychotherapeutic drugs. Urogenital complaints (such as atrophic vaginitis) can be treated with bioadhesive vaginal moisturisers (Replens) or with vaginal oestriol and oestradiol preparations; in doing so, the prescribed dose must be adhered to.

For relief of hot flushes, on the basis of the reviewed studies (evidence levels have been mentioned), we recommend the following steps:

1. General measures such as reduction of caffeine and nicotine consumption, suitable clothing, avoidance of warmth, exercise in the fresh air, breathing and relaxation exercises, and a balanced diet.

2. Treatment trial with phytopreparations without ECa as a contraindication (however frequent disappointing effects).

3. Treatment trial with gestagens, preferably MPA or megestrol acatate.

4. Low-dose ET, for example with oestradiol patches or gel; CCEPT only in cardiovascularly healthy patients (note risk factors for ECa such as hypertension, diabetes, obesity, metabolic syndrome and PCO syndrome!)

5. On the refusal of hormonal treatment by the patient: opipramol or an SSRI such as venlafaxine.

Should it be found in further clinical trials that the risk of breast cancer is increased with gestagens, we will use ET instead of the previous CCEPT for our choice of HT in our clinical practice.

In the absence of well-designed studies, the choice of HT after ECa should be based on prognostic indicators, including depth of invasion, degree of differentiation, and cell type. These predictors can assist the physician to estimate the risk of recurrent tumours and can assist the patient to determine the degree of risk she is willing to assume on an individualised basis, and to compare potential benefits and risks.

\section{References}

Albertazzi P 2002 Management of hot flushes without oestrogen. Journal of the British Menopause Society 8 147-151.

Albrecht BH, Schiff I, Tulchinsky D \& Ryan KJ 1981 Objective evidence that placebo and oral medroxyprogesterone acetate therapy diminish menopausal vasomotor flushes. American Journal of Obstetrics and Gynecology 139 631-635.

American Cancer Society 2002 Cancer Facts and Figures. Atlanta, GA: American Cancer Society.

American College of Obstetricians and Gynecologists (ACOG) 1993 Estrogen Replacement Therapy and Endometrial Cancer. Committee Opinion 126. Washington, DC: ACOG.

American College of Obstetricians and Gynecologists (ACOG) 2001 Hormone replacement therapy in women treated for endometrial cancer. Committee Opinion 235. International Journal of Gynecology and Obstetrics 73 283-284.

Arbeitsgemeinschaft Bevölkerungsbezogener Krebsregister in Deutschland 2002 Krebs in Deutschland -Häufigkeiten und Trends, 3rd edn. Saarbrücken.

Baker DP 1990 Estrogen replacement therapy in patients with previous endometrial carcinoma. Comprehensive Therapy 6 35.

Beresford SAA, Weiss NS, Voigt LF \& McKnight B 1997 Risk of endometrial cancer in relation to use of oestrogen combined with cyclic progestagen therapy in postmenopausal women. Lancet 349 458-461.

Bertone E \& Weiderpass E 2000 Low dose oestrogens and endometrial cancer. Review. Journal of the British Menopause Society 6 89-92.

Birkhäuser M, Braendle W, Keller PJ, Kiesel L, Kuhl H \& Neulen J 2003 Zürcher Gesprächskreis. Frauenarzt 44 390-394.

Bjarnason K, Cerin A, Lindgren R \& Weber T 1999. The Scandinavian Long Cycle Study Group. Adverse endometrial effects during long cycle hormone replacement therapy. Maturitas 32 161-170.

Bryant GW 1990 Administration of estrogens in patients with a previous diagnosis of endometrial adenocarcinoma (letter). Southern Medical Journal 83 725-726.

Bullock JL, Massey FM \& Gambrell RD Jr 1975 Use of medroxyprogesterone acetate to prevent menopausal symptoms. Obstetrics and Gynecology 46 165-168.

Carr JA, Schoon PA \& Look KY 1996 An atypical recurrence of endometrial carcinoma following estrogen replacement therapy. Gynecologic Oncology 7 575-580. 
Chapman JA, DiSaia PJ, Osann K, Roth PD, Gillotte DL \& Berman ML 1996 Estrogen replacement in surgical stage I and II endometrial cancer survivors. American Journal of Obstetrics and Gynecology 175 1195-1200.

Chlebowski RT \& McTiernan A 1999 Elements of informed consent for hormone replacement therapy in patients with diagnosed breast cancer. Journal of Clinical Oncology 17 $140-142$.

Creasman WT 1999 HRT and women who have had breast or endometrial cancer. Journal of Epidemiology and Biostatistics $4217-225$.

Creasman WT, Henderson D, Hinshaw W \& Clarke-Pearson DL 1986 Estrogen replacement therapy in the patient treated for endometrial cancer. Obstetrics and Gynecology 67 326-330.

Emons G (for the German Society of Senology) 2002. Hormonsubstitution nach Mammakarzinom. Eine Konsensusempfehlung. Gynäkologe 35 1114-1116.

Emons G \& Schulz K-D 1998 Ätiologie des Endometriumkarzinoms. In Endometrium und Hormonsubstitution, pp 47-54. Eds AO Mueck \& T Römer. Stuttgart: Georg Thieme Verlag.

Emons G, Fleckenstein G, Hinney B, Huschmand A \& Heyl W 2000 Hormonal interactions in endometrial cancer. Endocrine-Related Cancer 7 227-242.

Emons G, Gründker C \& Hanf V 2003 Are estrogens carcinogens? Gynäkologe 36 182-189.

Erkkola R, Kumento U, Lehmuskowski S, Mattila L \& Mustonen M 2002 No increased risk of endometrial hyperplasia with fixed long-cycle hormone replacement therapy after two years. Journal of the British Menopause Society 8 155-156.

Farish E, Barnes JF, O’Donoghue F, Fletcher CD, Ekevall K \& Hart DM 2000 The role of megestrol acetate as an alternative to conventional hormone replacement therapy. Climacteric 3 125-134.

German Society of Endocrinology 1988 Konsensus: Östrogen-/ Gestagen-Substitution während und nach den Wechseljahren. Deutsches Ärzteblatt 85 B-1322-1325.

German Society of Endocrinology 1996 Konsensus: strogen-/ Gestagen-Substitution während und nach den Wechseljahren. Endokrinologie-Informationen 20 122-125.

Glazier MG \& Bowman MA 2001 A review of the evidence for the use of phytoestrogens as a replacement for traditional estrogen replacement therapy. Archives of Internal Medicine 161 1161-1172.

Grady D, Gebretsadik T, Kerlikowski K, Ernster V \& Petitti D 1995 Hormone replacement therapy and endometrial cancer risk: a meta-analysis. Obstetrics and Gynecology 85 304-315.

Guttuso T, Kurlan R, McDermott MP \& Kieburtz K 2003 Gabapentin's effects on hot flashes in postmenopausal women: a randomised controlled trial. Obstetrics and Gynecology 101 337-345.

Hill DA, Weiss NS, Beresford SAA, Voigt LF, Daling JR, Stanford JL \& Self S 2000 Continuous combined hormone replacement therapy and risk of endometrial cancer. American Journal of Obstetrics and Gynecology 183 1456-1461.

Hillard T 2000 Serving without stimulation. Journal of the British Menopause Society (Suppl 2) 6 11-13.
Johnson EB, Muto MG, Yanushpolsky EH \& Mutter GL 2001 Phytoestrogen supplementation and endometrial cancer. Obstetrics and Gynecology 98 947-950.

Kenemans P 2000 Postmenopausal sex hormones and cancer of the endometrium and breast. Journal of the British Menopause Society 6 (Suppl 3) 4-9.

Kloosterboer HJ \& Sands R 2000 Intracinology: the secret of the tissue-specificity of tibolone. Journal of the British Menopause Society 6 (Suppl 2) 23-27.

Lauritzen C 1993 Östrogensubstitution in der Postmenopause vor und nach behandeltem Genital- und Mammakarzinom. In Menopause und Hormonsubstitution heute, pp 76-80. Ed C Lauritzen. Basel: Aesopus Verlag.

Lee RB, Burke TW \& Park RC 1990 Estrogen replacement therapy following treatment for stage I endometrial carcinoma. Gynecologic Oncology 36 189-191.

Liehr JG 2000 Is estradiol a genotoxic mutagenic carcinogen? Endocrine Reviews 21 40-54.

Loprinzi CL, Michalek JC, Quella SK, O'Fallon JR, Hatfield AK, Nelimark RA, Dose AM, Fischer T, Johnson C \& Klatt NE 1994 Megestrol acetate for the prevention of hot flashes. New England Journal of Medicine 331 247-252.

Marsden J 2002 Hormone replacement therapy and breast cancer. Lancet Oncology 3 303-311.

Mikkola TS \& Clarkson TB 2002 Estrogen replacement therapy, atherosclerosis, and vascular function. Cardiovascular Research 53 605-619.

Morrison JC, Martin DC, Blair RA, Anderson GD, Kincheloe BW, Bates GW, Hendrix JW, Rivlin ME, Forman EK, Propst MG \& Needham R 1980 The use of medroxyprogesterone acetate for relief of climacteric symptoms. American Journal of Obstetrics and Gynecology 138 99-104.

Mueck AO \& Seeger H 2002 Statins and menopausal health. Journal of the British Menopause Society 8 141-146.

Mueck AO \& Seeger H 2003 Smoking, estradiol metabolism and hormone replacement therapy. Drug Research 1 1-11.

Mueck AO \& Stoll K-D 2001 Opipramol bei menopausalem Syndrom als Alternative bei Kontraindikationen gegen Hormonsubstitution. In Opipramol, Sigmaligand und stimmungsaufhellendes Anxiolytikum, pp 137-146. Eds WE Müller \& HJ Möller. Neu-Isenburg, Germany: LinguaMed Verlag.

Mueck AO, Seeger H, Haasis R, Gohlke-Bärwolf C, Schieber M, Schuchert A \& Meinertz T 1999 Effect of oral vs. transdermal estradiol on cGMP during exercise in women with coronary artery disease - randomized, double-blind, placebo-controlled cross over study. Circulation 100 (Suppl 18) 1386.

Mueck AO, Seeger H \& Wallwiener D 2002 Impact of hormone replacement therapy on endogenous estradiol metabolism in postmenopausal women. Maturitas 43 87-93.

Mueck AO \& Wallwiener D 2003 Hormonsubstitution nach Brustkrebs. Medizinische Welt 51-56.

Natrajan PK, Soumakis K \& Gambrell RD 1999 Estrogen replacement therapy in women with previous breast cancer. American Journal of Obstetrics and Gynecology 288-295.

North American Menopause Society (NAMS) 2000 The role of isoflavones in menopausal health: consensus opinion of the North American Menopause Society. Menopause 7 215-229. 
North American Menopause Society (NAMS) 2003 Estrogen and progestogen use in the peri- and postmenopausal women: September 2003 position statement of the North American Menopause Society. Menopause 10 497-506.

Oehler MK, Brand A \& Wain GV 2003 Molecular genetics and endometrial cancer. Journal of the British Menopause Society $927-31$.

Persson I, Weiderpass E, Bergkvist L, Berström R \& Schairer C 1999 Risks of breast and endometrial cancer after estrogen and estrogen-progestin replacement. Cancer Causes Control $10253-260$

Pike MC, Peters RK, Cozen W, Probst-Hensch NM, Felix JC, Wan PC \& Mack TM 1997 Estrogen-progestin replacement therapy and endometrial cancer. Journal of the National Cancer Institute 89 1110-1116.

Preventive Services Task Force 1996 Guide to Clinician Preventive Services: Report of the US Preventive Services Task Force, 2nd edn. Baltimore, MD: Williams \& Wilkins.

Pritchard KI, Khan H \& Levine M (for the Steering Committee on Clinical Practice Guidelines for the Care and Treatment of Breast Cancer) 2002 Clinical practice guidelines for the care and treatment of breast cancer. 14. The role of hormone replacement therapy in women with a previous diagnosis of breast cancer. CMAJ 166 1017-1022.

Quella SK, Loprinzi CL, Sloan JA, Vaught NL, DeKrey WL, Fischer T, Finck G, Pierson N \& Pisansky T 1998 Long term use of megestrol acetate by cancer survivors for the treatment of hot flashes. Cancer 82 1784-1788.

Rabe T, Mueck AO, Deuringer FU \& Runnebaum B 1997 Spacing out of progestin - efficacy, tolerability and compliance of two regimens for hormonal replacement in the late postmenopause. Gynecological Endocrinology 11 383-392.

Römer T \& Mueck AO 1998 Endometrium und Hormonsubstitution. Stuttgart, Germany: Georg Thieme Verlag.

Schiff I, Tulchinsky D, Cramer D \& Ryan KJ 1980 Oral medroxyprogesterone in the treatment of postmenopausal symptoms. JAMA 244 1443-1445.

Seeger H, Wallwiener D \& Mueck AO 2003 Comparison of the effect of progesterone, medroxyprogesterone acetate and norethisterone on the proliferation of human breast cancer cells. Journal of the British Menopause Society 9 36-39.

Sturdee DW 2003. Is 'HRT' the correct terminology? Journal of the British Menopause Society 953.

Sturdee DW, Ulrich LG, Barlow DH, Wells M, Campbell MJ, Vessey MP, Nielsen B, Anderson MC \& Bragg AJ 2000 The endometrial response to sequential and continuous combined oestrogen-progestogen replacement therapy. British Journal of Obstetrics and Gynaecology 109 1392-1400.

Suriano KA, McHale M, McLaren CE, Li KF, Re A \& DiSaja PJ 2001 Estrogen replacement therapy in endometrial cancer patients: a matched control study. Obstetrics and Gynecology 97 955-960.

Weiderpass E, Adami HO, Baron JA, Magnusson C, Bergström R, Lindgren A, Correia N \& Persson I 1999 Risk of endometrial cancer following estrogen replacement with and without progestins. Journal of the National Cancer Institute 91 1131-1137. 